\title{
Thermo-physiological properties of polyester-cotton plated fabrics in relation to fibre linear density and yarn type
}

\author{
Y Jhanji ${ }^{1 *}\left(\mathbb{D}\right.$, D Gupta ${ }^{2}$ and V K Kothari ${ }^{2}$
}

*Correspondence:

yjhanji@gmail.com

${ }^{1}$ Department of Fashion

and Apparel Engineering,

The Technological Institute

of Textiles and Sciences,

Bhiwani 127 021, India

Full list of author information

is available at the end of the article

\begin{abstract}
Thermo-physiological properties of textiles are crucial in determining the heat and moisture transport from skin to environment and in the assessment of overall wearer comfort. Engineering fabrics with desirable thermo-physiological properties suited for specific applications such as active wear, intimate wear is a big challenge for textile manufacturers as gamut of fibre, yarn and fabric parameters are known to influence the thermo-physiological properties. The present study was undertaken with an aim to explore suitable combination of fibre and yarn variables for engineering polyester-cotton plated fabrics with good thermo-physiological properties. Categorical variables i.e. outer layer yarn type and inner layer fibre linear density were found to affect the thermal, moisture vapour and liquid moisture transfer properties of developed test samples. Fabrics knitted with carded yarn and polyester fibre of high linear density showed high thermal resistance and would feel warmer on initial skin contact owing to low thermal absorptivity. However, the air permeability and moisture vapour transmission rate increased with combination of combed cotton yarn in the outer and coarse polyester fibre in the inner layer. Combed yarn fabrics were superior in trans planar wicking compared to carded yarn fabrics which showed higher water absorbency and would be slow drying fabrics.
\end{abstract}

Keywords: Carded yarn, Combed yarn, Plated fabric structures, Thermo-physiological properties, Yarn linear density, Yarn types

\section{Introduction}

Thermo-physiological properties of textiles greatly determine the transport of heat, moisture vapour and liquid moisture from skin to environment through clothing and are therefore, crucial to provide comfortable microclimate to the wearer. Clothing layer worn next to skin should have two important properties: the initial and the foremost property is to absorb the perspiration from the skin surface and second property is to transfer moisture to atmosphere and make the wearer feel comfortable. Diffusion and wicking are the two means by which moisture gets transferred to the atmosphere. Concentration gradient is the driving force which causes moisture diffusion from region of high concentration to low concentration. Wicking involves the motion of liquid moisture in void spaces between fibres in a yarn (Patil et al. 2009) and is significantly affected by the liquid retention in the voids. The thermal properties along with air permeability and

(C) 2015 Jhanji et al. This article is distributed under the terms of the Creative Commons Attribution 4.0 International License (http:// creativecommons.org/licenses/by/4.0/), which permits unrestricted use, distribution, and reproduction in any medium, provided you give appropriate credit to the original author(s) and the source, provide a link to the Creative Commons license, and indicate if changes were made. 
drying ability of textiles are equally important in determining the overall wearer comfort. Thermal resistance and thermal absorptivity-objective measure of warm-cool feeling on fabric's brief initial skin contact determines the application area of fabrics. Fabrics with high thermal insulation and providing warmer feeling are preferred choice as winter wear. However, lower thermal insulation, cooler feeling on initial skin contact, higher air permeability and quick drying ability are the desirable properties for fabrics intended as summer wear.

Thermo-physiological properties of textiles are influenced by several fibre, yarn and fabric parameters. Thermal resistance of textile materials is not determined solely by thermal conductivity of the fibre but depends largely on fabric thickness. Other factors that have an influence are the packing density of fabric structure and fibre fineness (Holcombe and Hoschke 1983). Bulk properties of fabrics particularly thickness and porosity influence the air permeability and drying ability of textiles. Sweat transmission and absorption properties of clothing are affected by fibre properties, yarn and fabric structural parameters, chemical processing and clothing design properties (Oner et al. 2013). Many parameters such as fibre type, composition, number of fibres in yarn cross-section and fibre configuration in yarn determine the wicking performance of spun and filament yarns (Das et al. 2007a, b). Governing factor for liquid transfer properties are thickness and free surface energy as well as size and shape of fibres (Cimilli et al. 2010). Absorption of water by fibres depends on total amount of water that can be absorbed regardless of time and the speed of water uptake. Yarn characteristics such as structure, linear density and twist have considerable effect on the wicking rate of water. Wicking of liquids in yarns mainly take place through capillary spaces formed by fibres (Nyoni and Brook 2006). Capillary sizes during liquid rise can be affected by non-rigid yarn structure which results in lateral stresses due to capillary flow (Ansari and Kish 2000). Increase in yarn roughness due to random arrangement of its fibres also affects water transport properties of fabrics by the way it influences the continuity of capillaries and effective advancing contact angle of water on yarn (Kissa 1996).

Plated knit structures are characterized by distinct yet integrated inner and outer layers which enables the structure to move liquid moisture from wearer's skin through inner layer (next to skin) by capillary action to outer (exposed to environment) layer and helps to create substantial moisture concentration gradient between the two fabric layers. Thus, plated fabrics can be designed by selection of distinct fibre and yarn components in the two layers to ensure that inner layer serves as diffusing layer and the outer layer as absorptive layer, absorbing the moisture transferred from the inner layer.

Several researchers have attempted to study the effect of fibre and yarn parameters on comfort characteristics of woven and knitted fabrics. Varshney et al. (2010) studied the effect of fibre linear density on physiological properties of polyester woven fabrics and observed an increase in thermal resistance, trans planar wicking, air and water vapour permeability with fibre decitex. However they observed that thermal conductivity, thermal absorptivity and spreading speed of water drop decreased with increase in fibre coarseness. Das et al. (2008) reported reduction in air and water vapour permeability through the fabrics but increased wicking properties with the decrease in fibre diameter in their studies on micro-denier and normal denier filament fabrics. Ramakrishnan et al. (2009) compared the comfort properties of micro denier and normal denier viscose yarn knitted fabrics and observed better water absorbency and wicking for micro denier yarn 
knitted fabrics. Raj and Sreenivasan (2009) reported that the cotton fibre fineness had negative correlation with air permeability of fabrics woven from yarns having the same count and twist and suggested this outcome of reduced air spaces in the fabrics made from finer fibres. Oglakcioglu and Marmarali (2010) studied the effect of yarn type on thermal comfort properties of cotton knitted fabrics and observed that fabrics knitted with double plied yarn had higher thermal conductivity, thermal absorptivity and thermal resistance compared to single plied yarn fabrics. Singh and Nigam (2013) compared carded, combed and compact spun yarn woven fabrics for their comfort performance and reported that compact weft yarn fabrics showed high water vapour permeability while carded yarn fabrics showed higher thermal insulation. Ozdil et al. (2007) studied the thermal comfort properties of carded and combed yarn rib knitted fabrics and observed an increase in thermal conductivity and water vapour permeability of fabrics knitted with combed yarns. Nasrin and Nahida (2011) reported that combed yarns were stronger, less hairy and more uniform than carded yarns. Erdumlu and Saricam (2013) studied the wicking and drying properties of vortex spun yarns and knitted fabrics in comparison with ring-spun yarns and fabrics. They observed that vortex spun yarn had lower yarn and fabric wicking values and water absorbency rate than ring-spun yarns. Tyagi et al. (2009) studied the influence of yarn type on thermal comfort properties of woven fabrics and concluded that Murata Jet Spinning (MJS) yarn fabrics showed higher absorbency, air and water vapour permeability but lower wick ability compared to ring yarn fabrics. The review of published literature suggests that researches are mainly focused on studying the effect of fibre and yarn parameters on comfort properties of woven and knitted fabrics. However, studies on the thermo-physiological properties of plated knits are very limited although the structures are fast becoming preferred choice as intimate wear owing to flexibility in engineering fabrics with different fibre and yarn combinations in the two distinct layers. Moreover, none of the reported studies suggest the desirable fibre and yarn combination in the two layers to engineer fabrics suited for particular environmental conditions. The present study was, therefore undertaken to explore the field further and to determine the effect of inner layer fibre linear density and the outer layer yarn type on thermo-physiological properties of plated knits.

\section{Methods}

Materials

Cotton and polyester fibres were used in the production of the yarn samples. Cotton carded and combed roving of 0.9 hank was used to spin 24 Ne single ring spun carded and combed yarns on blowroom. Polyester fibre of five different linear density $(1.1,1.3$, 1.5, 2.2 and 3.3 decitex) and circular profile were used to spin five $24 \mathrm{Ne}$ single ring spun yarns on 6/S LMW pilot plant ring frame. The seven yarn samples in totality were used for the preparation of ten single jersey plated fabrics. All the samples were prepared in plating relationship with carded and combed ring spun cotton yarn in the outer (exposed to environment) layer and polyester fibres of varying fibre linear density in the inner (next to skin) layer. The fabric samples were prepared on hand operated flatbed knitting machine (Elex, China) with machine gauge of 14, needle bed of 42 inches and 588 needles in each bed. The machine had front and rear needle beds but only the front bed was utilized for preparation of test samples. All the machine parameters were kept constant 
to obtain the fabrics of same cover factor. The fibre specifications and process parameters are presented in Table 1. Table 2 summarizes the details of prepared test fabrics.

\section{Characterization}

The yarn diameter was measured by SMZ1500 digital microscope (Nikon Digital Sight DS, Japan) at 20 randomly selected places along the yarn length. Average 20 readings was taken as yarn diameter. Yarn hairiness was determined by Zweigle Hairiness meter (Model G566). The test length of $200 \mathrm{~m}$ was taken for the hairiness measurement. Hairs $>3 \mathrm{~mm} / 200 \mathrm{~m}$ was regarded as index of hairiness level or hairiness count. The thickness of fabrics was determined on Essdiel thickness gauge at a pressure of $20 \mathrm{gf} / \mathrm{cm}^{2}$ according to ASTM D 1777-96, 2007. Aerial density was determined according to ASTM D-1059 and was obtained by dividing the weight of test sample with the area of the sample. Fabric bulk density was calculated as the ratio between fabric weight per unit area $\left(\mathrm{g} / \mathrm{m}^{2}\right)$ and thickness $(\mathrm{mm})$ as shown in the following equation:

$$
\text { Bulk density }\left(\mathrm{kg} / \mathrm{m}^{3}\right)=\frac{\text { weight } / \text { area }}{\text { thickness }}
$$

Fabric porosity was determined using the following equation:

$$
\text { Porosity }(\%)=\frac{\left(\rho_{0}-\rho\right)}{\rho_{0}} \times 100 \%
$$

where $\rho_{0}$, is the fibre density $\left(\mathrm{kg} / \mathrm{m}^{3}\right)$ and $\rho$, the fabric density $\left(\mathrm{kg} / \mathrm{m}^{3}\right)$.

Table 1 Fibre specifications and process parameters

\begin{tabular}{ll}
\hline Cotton (J-34) & Upper half mean length-29.2 mm \\
Polyester & Mean length-24.3 mm, Micronaire-4.32 \\
& Staple length-44 mm \\
Roving hank & Fibre decitex-1.1,1.3, 1.5, 2.2 and 3.3 \\
Turns per inch & 0.9 \\
Yarn count (Ne) & 17.2 \\
Twist direction & $24 / 1$ \\
Spindle speed (rpm) & $\mathrm{Z}$ \\
\hline
\end{tabular}

Table 2 Details of plated knitted fabrics

\begin{tabular}{lll}
\hline Sample code & PET fibre linear density (decitex) & Yarn type \\
\hline RC1.1 & 1.1 & Carded \\
RM1.1 & 1.1 & Combed \\
RC1.3 & 1.3 & Carded \\
RM1.3 & 1.3 & Combed \\
RC1.5 & 1.5 & Carded \\
RM1.5 & 1.5 & Combed \\
RC2.2 & 2.2 & Carded \\
RM2.2 & 2.2 & Combed \\
RC3.3 & 3.3 & Carded \\
RM3.3 & 3.3 & Combed \\
\hline
\end{tabular}

Outer layer-C: cotton, inner layer-PET: polyester, PET fibre cross-section—circular, yarn spinning system—ring. 


\section{Thermal properties}

Thermal resistance (TR), thermal conductivity (TC) and thermal absorptivity (TA) of the fabric samples were evaluated on Alambeta (Sensora, Czech Republic). The instrument consists of a hot and cold plate, between which the fabric was positioned. Hot plate contacts fabric at a pressure of $200 \mathrm{~Pa}$. When the temperature of hot plate reaches the preset value, the thin film heat flux sensor senses the heat flow from hot plate to cold plate. Heat flux sensors detect the amount of heat flow from hot surface to cold surface through fabric. The heat flow value and thickness are used to calculate fabric conductivity and finally the thermal resistance.

\section{Air permeability}

Air permeability (AP) of the fabrics was measured on FX 3300 air permeability tester (TEXTEST AG, Switzerland) at a pressure of $98 \mathrm{~Pa}$ according to ASTM D737. A prescribed air pressure differential between the two surfaces of fabric is obtained by adjusting the rate of air flow that passes perpendicular through known fabric area. The main components of the air permeability tester are: test head for positioning the test sample, clamping system for securing the test specimen to the test head without any distortion, air pump to draw a steady flow of air perpendicularly through the test fabric and pressure gauge or manometer connected to the test head below the test sample to measure pressure drop across test sample in Pascals.

Moisture vapour transmission rate (MVTR)

Moisture vapour transmission rate of the test fabrics was determined by moisture vapour transmission cell (MVTR cell) (Grace, Cryovac division). The amount of water vapour transmitting through $100 \mathrm{~cm}^{2}$ area of fabric during a $24 \mathrm{~h}$ period can be determined with this instrument. Test sample was suspended across the centre of the cell with distilled water below and humidity sensing device above. Dry side was dehumidified as increase in the humidity level on a 0-100 arbitrary humidity meter scale at equal intervals of time was recorded. Readings were continued from 5 to 75 humidity at constant time intervals. Moisture vapour transmission rate of fabrics in $\mathrm{g} / \mathrm{m}^{2} / 24 \mathrm{~h}$ was obtained by the change in humidity at a time interval using the following equation:

$$
M V T R=\left(269 \times 10^{-7}\right)\left(\Delta R H \% \times \frac{1440}{t}\right) H
$$

where $\Delta R H \%$, is the average difference in successive \% RH values, $\mathrm{t}$, the time interval (minutes) and $\mathrm{H}$, the gram water per $\mathrm{m}^{3}$ of air at cell temperature.

Water absorbency and trans planar wicking of test samples was determined by Gravimetric Absorbency Tester (GATS). A circular specimen of area equal to the porous plate, was cut with the help of a die and weighed. The sample was then placed above the porous plate for the measurements. GATS include a fluid reservoir and a plastic tube linked to the sample platform. The fluid cell was filled with water, the die cut sample weighed and positioned on the specimen platform, which was connected to the fluid reservoir by flexible tubing The tests were conducted under a hydrostatic pressure head of zero $(\Delta \mathrm{P}=0)$. High speed data acquisition system is interfaced with the instrument. 
Labview software records the display and evaluates the outputs from the GATS. Imbibition of liquid water by the test specimen marks the beginning of the test. The fluid reservoir set on the electronic balance becomes lighter as fluid flows into fabric due to liquid absorption as the test progresses.

\section{Results and discussion}

Cotton carded and combed ring spun yarns and polyester yarns of varying fibre linear density were tested for their yarn diameter and hairiness (Table 3). Polyester-cotton fabrics with carded and combed cotton yarns in the outer and polyester yarn of varying fibre linear density in the inner layer were evaluated for their physical properties, air permeability, thermal, moisture vapour and liquid moisture transfer properties. Results are summarized in Tables 4, 5, 6, 7.

\section{Thermal absorptivity}

Thermal absorptivity for carded yarn fabrics (RC1.1-RC3.3) varied from 69.5 to $75.2 \mathrm{~W} \mathrm{~s}^{1 / 2} \mathrm{~m}^{-2} \mathrm{~K}^{-1}$ while that for combed yarn fabrics (RM1.1-RM3.3) varied from 72.2 to $78.1 \mathrm{~W} \mathrm{~s}^{1 / 2} \mathrm{~m}^{-2} \mathrm{~K}^{-1}$ (Table 5). Thermal absorptivity of samples made with carded yarns was lower as compared to that of combed yarn fabrics (Fig. 1) indicating that the fabrics

Table 3 Yarn properties

\begin{tabular}{lll}
\hline Description & $\begin{array}{l}\text { Yarn diameter } \\
(\mathbf{m m})\end{array}$ & $\begin{array}{l}\text { Uster yarn hairiness } \\
\mathbf{( H )}\end{array}$ \\
\hline Cotton ring carded & 0.215 & 22.21 \\
Cotton ring combed & 0.181 & 18.14 \\
Polyester ring carded (1.1 decitex) & 0.181 & 6.38 \\
Polyester ring carded (1.3 decitex) & 0.182 & 6.68 \\
Polyester ring carded (1.5 decitex) & 0.186 & 7.82 \\
Polyester ring carded circular (2.2 decitex) & 0.195 & 12.13 \\
Polyester ring carded (3.3 decitex) & 0.219 & 15.79 \\
\hline
\end{tabular}

Table 4 Physical properties of plated fabrics with varying fibre linear density and yarn type

\begin{tabular}{lllll}
\hline $\begin{array}{l}\text { Sample } \\
\text { code }\end{array}$ & $\begin{array}{l}\text { Thickness } \\
(\mathbf{m m})\end{array}$ & $\begin{array}{l}\text { Aerial density } \\
\left(\mathbf{g} / \mathbf{m}^{\mathbf{2}}\right)\end{array}$ & $\begin{array}{l}\text { Bulk density } \\
\left(\mathbf{k g} / \mathbf{m}^{\mathbf{3}}\right)\end{array}$ & $\begin{array}{l}\text { Porosity } \\
\mathbf{( \% )}\end{array}$ \\
\hline RC1.1 & 0.927 & 248 & 267.38 & 81.68 \\
RM1.1 & 0.925 & 260 & 281.08 & 80.75 \\
RC1.3 & 0.953 & 248 & 260.36 & 82.17 \\
RM1.3 & 0.930 & 261 & 280.64 & 80.77 \\
RC1.5 & 0.956 & 241 & 252.09 & 82.73 \\
RM1.5 & 0.935 & 262 & 280.21 & 80.80 \\
RC2.2 & 0.960 & 239 & 248.95 & 82.94 \\
RM2.2 & 0.95 & 248 & 261.05 & 82.11 \\
RC3.3 & 0.974 & 238 & 244.35 & 83.46 \\
RM3.3 & 0.962 & 251 & 260.91 & 82.55 \\
\hline
\end{tabular}

RC1.1—ring carded PET dtex 1.1, RM1.1 —ring combed PET dtex 1.1, RC1.3—ring carded PET dtex 1.3, RM1.3—ring combed PET dtex 1.3, RC1.5—ring carded PET dtex 1.5, RM1.5—ring combed PET dtex 1.5, RC2.2—ring carded PET dtex 2.2, RM2.2ring combed PET dtex 2.2, RC3.3—ring carded PET dtex 3.3, RM3.3—ring combed PET dtex 3.3. 
Table 5 Thermal properties of plated fabrics with varying fibre linear density and yarn type

\begin{tabular}{|c|c|c|c|}
\hline Sample code & $\begin{array}{l}\text { Thermal } \\
\text { absorptivity b } \\
\left(\mathrm{W} \mathrm{s}^{1 / 2} \mathrm{~m}^{-2} \mathrm{~K}^{-1} \text { ) }\right.\end{array}$ & $\begin{array}{l}\text { Thermal } \\
\text { resistance } R \\
\left(\times 10^{-3} \mathrm{~K} \mathrm{~m}^{2} \mathrm{~W}^{-1}\right)\end{array}$ & $\begin{array}{l}\text { Thermal } \\
\text { conductivity } \lambda \\
\left(\times 10^{-3} \mathrm{~W} \mathrm{~K}^{-1} \mathrm{~m}^{-1}\right)\end{array}$ \\
\hline $\mathrm{RC} 1.1$ & 75.2 & 41.7 & 30.5 \\
\hline RM1.1 & 78.1 & 35.0 & 33.4 \\
\hline $\mathrm{RC} 1.3$ & 73.9 & 43.6 & 31.0 \\
\hline RM1.3 & 76.2 & 36.9 & 32.8 \\
\hline RC1.5 & 73.2 & 44.2 & 30.9 \\
\hline RM1.5 & 75.8 & 40.2 & 31.9 \\
\hline $\mathrm{RC} 2.2$ & 70.2 & 44.3 & 32.8 \\
\hline $\mathrm{RM} 2.2$ & 75.9 & 40.8 & 32.8 \\
\hline $\mathrm{RC} 3.3$ & 69.5 & 46.2 & 29.2 \\
\hline RM3.3 & 72.2 & 42.8 & 30.1 \\
\hline
\end{tabular}

RC1.1—ring carded PET dtex 1.1, RM1.1_ring combed PET dtex 1.1, RC1.3-ring carded PET dtex 1.3, RM1.3-ring combed PET dtex 1.3, RC1.5-ring carded PET dtex 1.5, RM1.5-ring combed PET dtex 1.5, RC2.2 -ring carded PET dtex 2.2, RM2.2ring combed PET dtex 2.2, RC3.3 - ring carded PET dtex 3.3, RM3.3-ring combed PET dtex 3.3.

Table 6 Air permeability and moisture vapour transmission rate of plated fabrics with varying fibre linear density and yarn type

\begin{tabular}{|c|c|c|}
\hline $\begin{array}{l}\text { Sample } \\
\text { code }\end{array}$ & $\begin{array}{l}\text { Air permeability } \\
\left(\mathrm{cm}^{3} / \mathrm{cm}^{2} / \mathrm{s}\right)\end{array}$ & $\begin{array}{l}\text { Moisture vapour } \\
\text { transmission rate } \\
\left(\mathrm{g} / \mathrm{m}^{2} / 24 \mathrm{~h}\right)\end{array}$ \\
\hline RC1.1 & 70.6 & 7.25 \\
\hline RM1.1 & 78.9 & 8.39 \\
\hline $\mathrm{RC} 1.3$ & 74.7 & 7.66 \\
\hline RM1.3 & 81.9 & 8.43 \\
\hline $\mathrm{RC} 1.5$ & 88.6 & 7.89 \\
\hline RM1.5 & 95.9 & 8.52 \\
\hline $\mathrm{RC} 2.2$ & 89.9 & 8.43 \\
\hline RM2.2 & 96.3 & 8.66 \\
\hline RC3.3 & 120.5 & 9.46 \\
\hline RM3.3 & 126.2 & 9.81 \\
\hline
\end{tabular}

RC1.1 - ring carded PET dtex 1.1, RM1.1 —ring combed PET dtex 1.1, RC1.3—ring carded PET dtex 1.3, RM1.3-ring combed PET dtex 1.3, RC1.5—ring carded PET dtex 1.5, RM1.5—ring combed PET dtex 1.5, RC2.2—ring carded PET dtex 2.2, RM2.2ring combed PET dtex 2.2, RC3.3 - ring carded PET dtex 3.3, RM3.3—ring combed PET dtex 3.3.

would provide warm feeling on brief skin contact. The difference in thermal absorptivity for carded and combed yarn fabrics may be attributed to difference in carded and combed yarn structure. The presence of hair in carded yarn as supported by their high hairiness value (Table 3) results in the creation of thin air layer at contact interface thereby reducing the contact area between fabric surface and skin. The surface features of fabric have a great influence on warm-cool feeling than fabric structure. A rough fabric surface reduces the area of contact appreciably while a smoother surface increases the area of contact and heat flow thereby creating cooler feeling (Pac et al. 2001; Raj and Sreenivasan 2009) and thus the observed trend can be explained in this light.

As the inner layer polyester fibre linear density increased, corresponding decrease in thermal absorptivity was observed irrespective of the outer layer yarn type (Fig. 1). Coarse fibres of high linear density result in fabrics of higher thickness and in turn lower 
Table 7 Water uptake in Trans planar wicking

\begin{tabular}{|c|c|c|c|c|c|c|c|c|c|c|}
\hline \multirow{3}{*}{$\begin{array}{l}\text { Sample } \\
\text { code }\end{array}$} & \multicolumn{10}{|c|}{ Water uptake in trans planar wicking (g) } \\
\hline & \multicolumn{10}{|c|}{ Time (s) } \\
\hline & 10 & 20 & 30 & 40 & 50 & 60 & 70 & 80 & 90 & 100 \\
\hline $\mathrm{RC} 1.1$ & 0.66 & 1.28 & 1.81 & 2.26 & 2.58 & 2.79 & 2.90 & 2.95 & 2.98 & 3.02 \\
\hline RM1.1 & 0.68 & 1.29 & 1.92 & 2.46 & 2.83 & 3.11 & 3.13 & 3.20 & 3.25 & 3.28 \\
\hline $\mathrm{RC} 1.3$ & 0.68 & 1.26 & 1.79 & 2.24 & 2.58 & 2.78 & 2.91 & 2.99 & 3.03 & 3.06 \\
\hline RM1.3 & 0.69 & 1.31 & 1.98 & 2.52 & 2.85 & 3.13 & 3.14 & 3.23 & 3.25 & 3.28 \\
\hline $\mathrm{RC} 1.5$ & 0.69 & 1.26 & 1.79 & 2.25 & 2.59 & 2.79 & 2.94 & 3.01 & 3.04 & 3.07 \\
\hline RM1.5 & 0.72 & 1.32 & 2.01 & 2.61 & 2.94 & 3.13 & 3.17 & 3.23 & 3.26 & 3.29 \\
\hline RC2.2 & 0.73 & 1.21 & 1.71 & 2.25 & 2.59 & 2.84 & 2.98 & 3.02 & 3.05 & 3.08 \\
\hline RM2.2 & 0.51 & 1.12 & 1.92 & 2.44 & 2.67 & 2.89 & 3.04 & 3.08 & 3.12 & 3.14 \\
\hline RC3.3 & 0.30 & 1.12 & 2.08 & 2.84 & 3.27 & 3.42 & 3.49 & 3.55 & 3.59 & 3.63 \\
\hline RM3.3 & 0.53 & 1.56 & 2.35 & 2.96 & 3.28 & 3.48 & 3.55 & 3.62 & 3.65 & 3.66 \\
\hline
\end{tabular}

RC1.1-ring carded PET dtex 1.1, RM1.1—ring combed PET dtex 1.1, RC1.3—ring carded PET dtex 1.3, RM1.3-ring combed PET dtex 1.3, RC1.5 - ring carded PET dtex 1.5, RM1.5 —ring combed PET dtex 1.5, RC2.2 - ring carded PET dtex 2.2, RM2.2ring combed PET dtex 2.2, RC3.3-ring carded PET dtex 3.3, RM3.3—ring combed PET dtex 3.3.

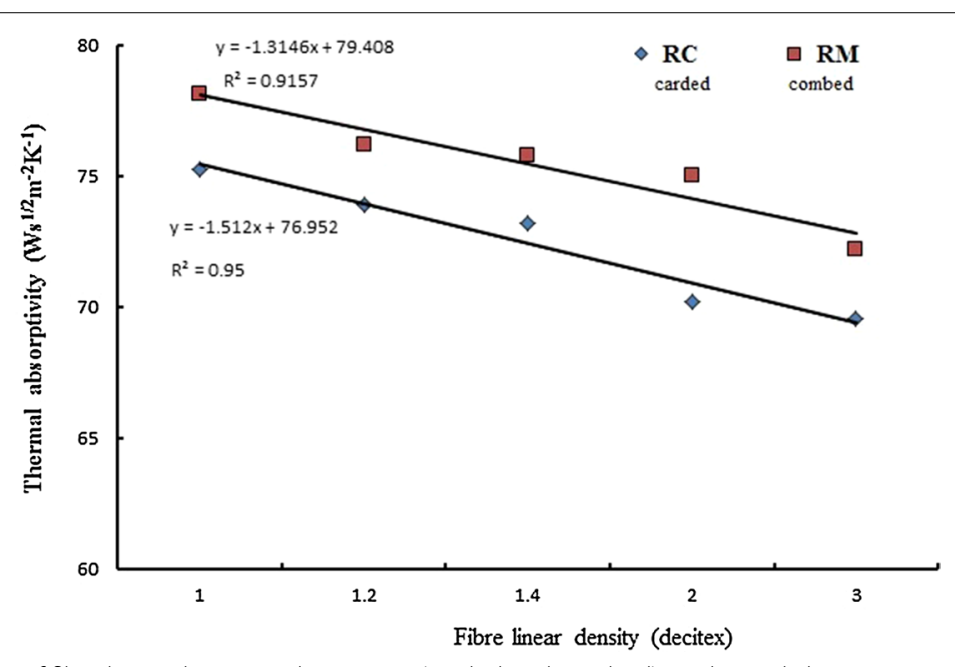

Fig. 1 Effect of fibre linear density and yarn type (carded and combed) on thermal absorptivity.

bulk density (Table 4) due to inverse relationship between bulk density and fabric thickness (Eq. 1). Reduction in bulk density resulted in corresponding decrease in thermal absorptivity owing to direct relationship between two parameters as indicated by the following equation:

$$
b=\sqrt{\lambda \rho c}
$$

where, $\mathrm{b}$ is the thermal absorptivity (W s ${ }^{1 / 2} \mathrm{~m}^{-2} \mathrm{~K}^{-1}$ ), $\lambda$, the thermal conductivity (W/ $\mathrm{mK}), \rho$, the fabric density and $\mathrm{c}$, the specific heat capacity $\left(\mathrm{J} \mathrm{kg}^{-1} \mathrm{~K}^{-1}\right)$

\section{Thermal resistance}

Thermal resistance of carded yarn fabrics (RC1.1-RC3.3) varied from $41.7 \times 10^{-3}$ to $46.2 \times 10^{-3} \mathrm{~K} \mathrm{~m}^{2} / \mathrm{W}$ while that of combed yarn fabrics (RM1.1-RM3.3) ranged from 
$35 \mathrm{~K} \mathrm{~m}^{2} / \mathrm{W} \times 10^{-3}$ to $42.8 \times 10^{-3} \mathrm{~K} \mathrm{~m}^{2} / \mathrm{W}$ (Fig. 2). Thermal resistance of porous textile structures is reported to be primarily determined by fabric thickness and enclosed still air which in turn depends on fibre fineness, fibre profile and yarn structure. Hairy structure of carded yarn fabrics enable entrapment of still air, air being good thermal insulator offers high thermal insulation for carded yarn fabrics. Moreover, higher yarn diameter of carded yarn results in thicker fabrics. Hence, increased entrapped air in structure and fabric thickness collectively contributes towards increased thermal resistance of carded yarn fabrics. Results are in accordance with the findings of Ozdil et al. (2007).

Incorporation of coarser polyester fibres in the inner layers of plated fabrics resulted in improved thermal resistance for both carded (RC1.1-RC3.3) and combed yarn fabrics (RM1.1-RM3.3) (Fig. 2). This may be attributed to the increase in fabric thickness and porosity (Table 4 ) with the increase in fibre linear density. High coefficient of determination (0.90) and (0.96) for carded and combed yarn fabrics respectively suggested positive linear relationship between fibre linear density and thermal resistance. The findings indicate that fibre and yarn combination that would result in high thermal resistance of plated fabrics are polyester fibre of high linear density and carded ring yarns compared to combination of polyester fibre of lower linear density and combed yarns.

\section{Air permeability}

Air permeability of carded yarn fabrics $\left(70.6-120.5 \mathrm{~cm}^{3} / \mathrm{cm}^{2} / \mathrm{s}\right)$ was found to be lower as compared to their combed yarn counterparts $\left(78.9-126.2 \mathrm{~cm}^{3} / \mathrm{cm}^{2} / \mathrm{s}\right)$ as shown in Fig. 3 . The presence of protruding hair fibres in carded yarn fabrics (RC1.1-RC3.3) can block the inter yarn pores thereby lowering the air permeability. However, the absence of hairs in combed yarn allows unrestricted passages of air through inter yarn pores and thus combed yarn fabrics (RM1.1-RM3.3) showed higher air permeability.

An increase in polyester fibre linear density from $1.1 \mathrm{dtex}$ to $3.3 \mathrm{dtex}$ resulted in corresponding increase in air permeability of carded $(\mathrm{RC} 1.1<\mathrm{RC} 1.3<\mathrm{RC} 1.5<\mathrm{RC} 2.2<\mathrm{R}$ C3.3) and combed yarn fabrics (RM1.1 < RM1.3 < RM1.5 < RM2.2 < RM3.3) (Fig. 3). The increase in air permeability with fibre linear density can be attributed to increasing

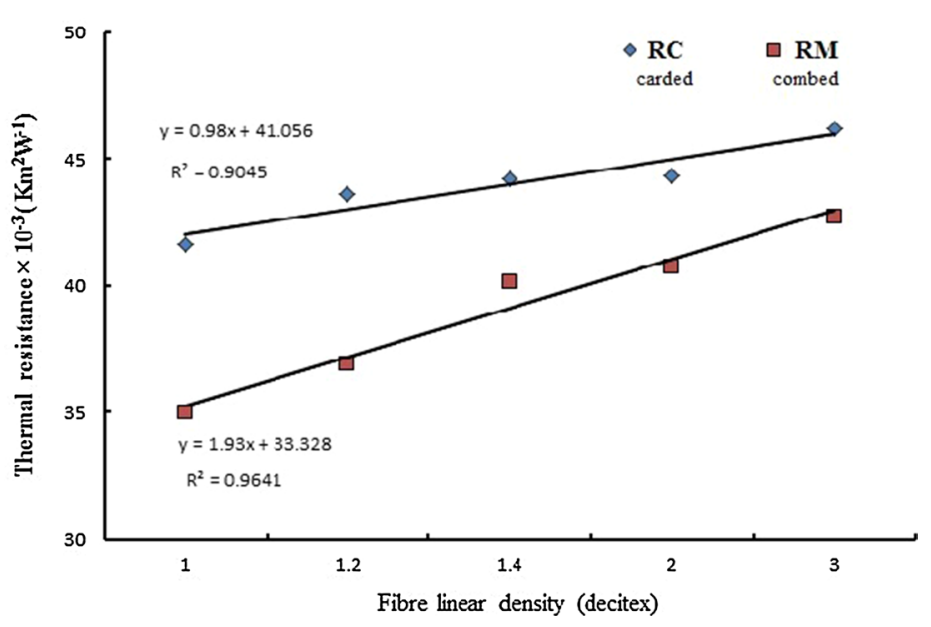

Fig. 2 Effect of fibre linear density and yarn type (carded and combed) on thermal resistance. 


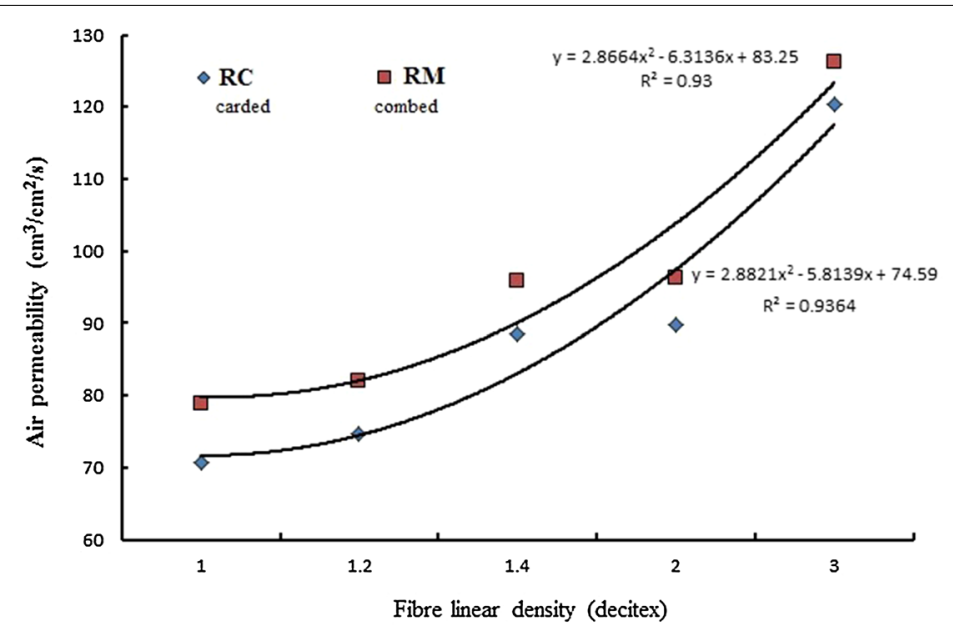

Fig. 3 Effect of fibre linear density and yarn type (carded and combed) on air permeability.

yarn diameter with increase in fibre linear density. This in turn results in reduced specific surface area. Lower the specific surface area, lesser the drag resistance to passage of air through fabric and hence the observed increase in air permeability with the increase in fibre linear density. High porosity of plated fabrics knitted with fibres of higher linear density may also account for the increased air permeability. Other researchers (Raj and Sreenivasan 2009; Varshney et al. 2010) have also reported similar results in their studies.

\section{Moisture vapour transmission rate}

As per Fig. 4, moisture vapour transmission rate of fabrics produced from carded yarns fabrics (RC1.1-RC3.3) varied from 7.25 to $9.46 \mathrm{~g} / \mathrm{m}^{2} / 24 \mathrm{~h}$ while that for combed yarn fabrics (RM1.1-RM3.3) ranged from 8.39 to $9.81 \mathrm{~g} / \mathrm{m}^{2} / 24 \mathrm{~h}$. The lower values for moisture vapour transmission rate of carded yarn fabrics may be attributed to the difference in the structure of carded and combed yarns, particularly the difference in hairiness values for the same. Moisture transfer through available free spaces in the fabrics occurs rapidly but if the free spaces are clogged, they may not provide easy passage for water vapour transfer thereby delaying the moisture transfer. Blocking of inter yarn spaces as a consequence of hairy structure of carded yarn would restrict the moisture vapour transmission through fabrics. Ozdil et al. (2007) reported similar results.

Table 6 shows that moisture vapour transmission rate of carded and combed yarn fabrics decreased with decrease in the fibre linear density. Positive correlation was observed between fibre linear density and moisture vapour transmission rate as indicated by high values of coefficient of determination (Fig. 4). As the polyester fibre become finer, yarn diameter reduces with corresponding increase in specific surface area (Table 3). Higher specific surface area offers more resistance to transmission of moisture vapour and hence the observed decrease in moisture vapour transmission rate with increase in fibre fineness. 


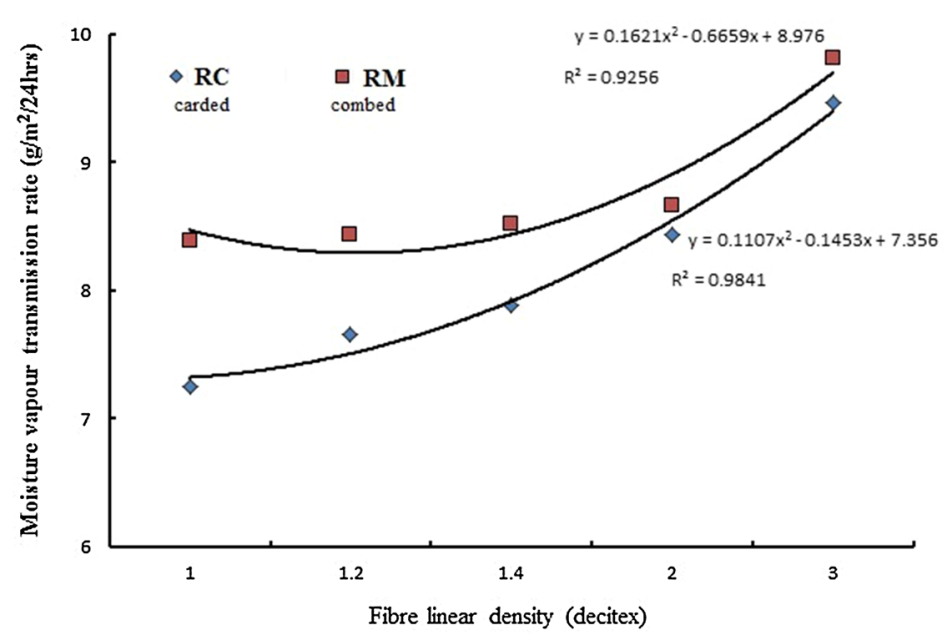

Fig. 4 Effect of fibre linear density and yarn type (carded and combed) on moisture vapour transmission rate.

\section{Trans planar wicking}

Figures 5 and 6 show the effect of yarn type and fibre linear density on trans planar wicking of test samples. Combed yarn fabrics (RM1.1-RM3.3) showed higher values of trans planar wicking compared to their carded yarn counterparts (RC1.1-RC3.3) (Fig. 5a). Continuous, less tortuous and small diameter capillaries are most effective in liquid transfer through capillary wicking (Das et al. 2007a, b; Das et al. 2009). Low yarn diameter and in turn high packing coefficient of combed yarn compared to carded yarn promote the formation of capillaries of small diameter. Lower the capillary diameter, greater will be the pressure created inside the capillary providing means for liquid flow. High
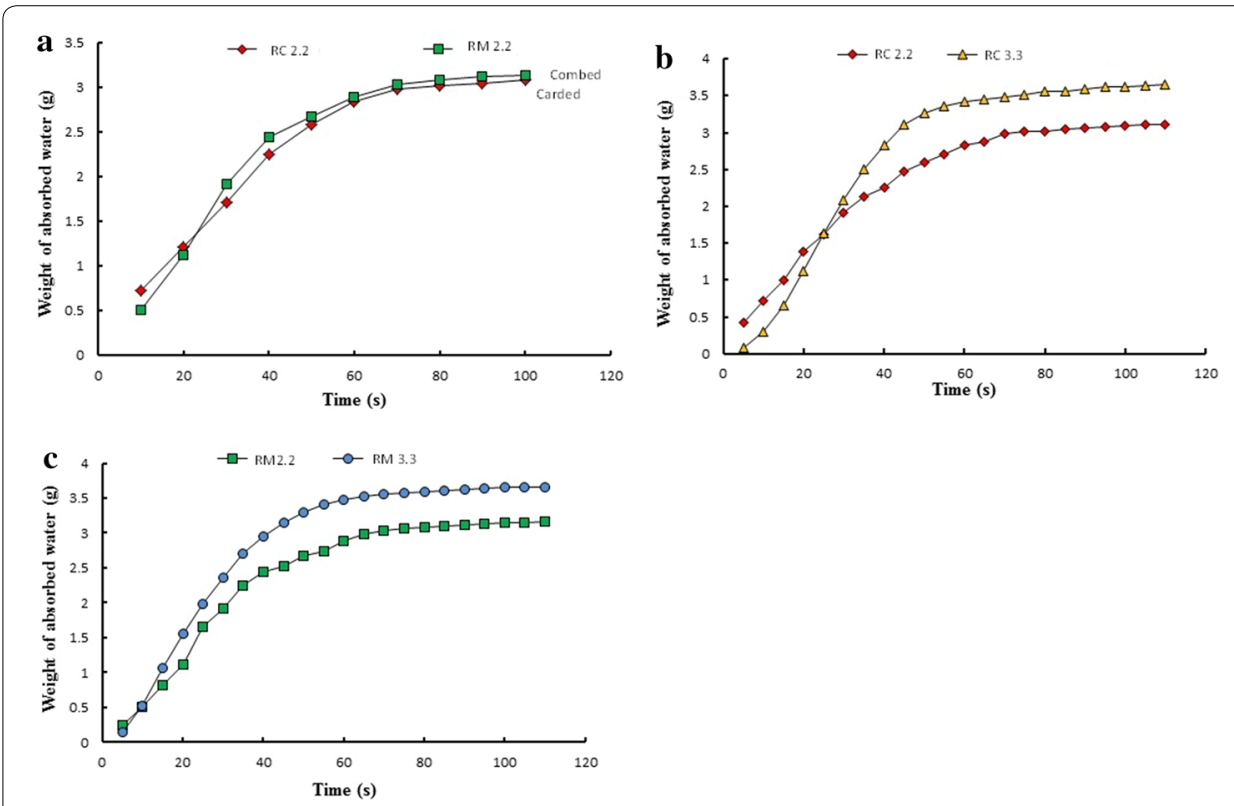

Fig. 5 Effect of $\mathbf{a}$ yarn type $\mathbf{b}$ fibre linear density of carded yarn fabrics $\mathbf{c}$ fibre linear density of combed yarn fabrics on trans planar wicking. 


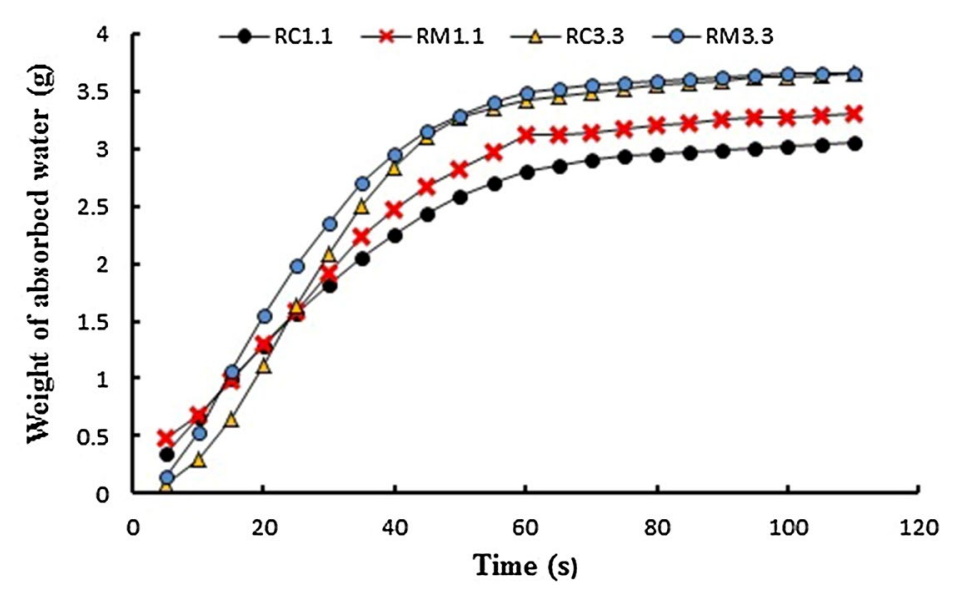

Fig. 6 Effect of fibre linear density on trans planar wicking of carded and combed yarn fabrics.

trans planar wicking of combed yarn fabrics is a result of capillaries of smaller diameter. The argument is supported by Laplace equation which gives the magnitude of capillary pressure (P) developed in capillary of radius $R_{c}$ :

$$
P=\frac{2 \gamma_{L V} \operatorname{Cos} \theta}{R_{c}}
$$

where, $\gamma_{L V}$ is the tension at interface between liquid and vapor, $\theta$, the angle of contact between liquid drop and solid surface.

Moreover, hairy structure of carded yarn may disrupt the continuity of capillaries; combed yarn on the other hand seems to be forming more continuous capillaries owing to more uniform and less hairy structure. High trans planar wicking of combed yarn fabrics can therefore be explained well in the light of above arguments.

Figures $5 \mathrm{~b}, \mathrm{c}$ and 6 shows the effect of polyester fibre linear density on trans planar wicking of carded (RC1.1-RC 3.3) and combed yarn fabrics (RM1.1-RM3.3). It was observed that trans planar wicking decreased with the decrease in polyester fibre linear density. As the fibre linear density decreases, number of fibres in the yarn cross-section increases resulting in large number of capillaries of small diameter (Das et al. 2008). Creation of smaller capillaries may create sufficient drag slowing the liquid movement (Varshney et al. 2010) and hence lower trans planar wicking of fabrics (RM 1.1 and RC1.1) knitted with finer fibres.

\section{Water absorbency}

Comparison of carded and combed yarn fabrics for water absorbency reveals that carded yarn fabrics (RC1.1-RC3.3) showed higher water absorbency as compared to their combed yarn counterparts (RM1.1-RM3.3) (Fig. 7). Water absorption through the inter fibre and inter yarn channels is dependent on fabric's bulk properties particularly, fabric thickness, aerial density and porosity which govern the weight of water initially absorbed and held by fabrics (Behera et al. 1997). High fabric thickness along with high fabric porosity, leads to increased air volume fraction resulting in more water entrapment by pores, and hence, high water absorbency of carded yarn fabrics. 


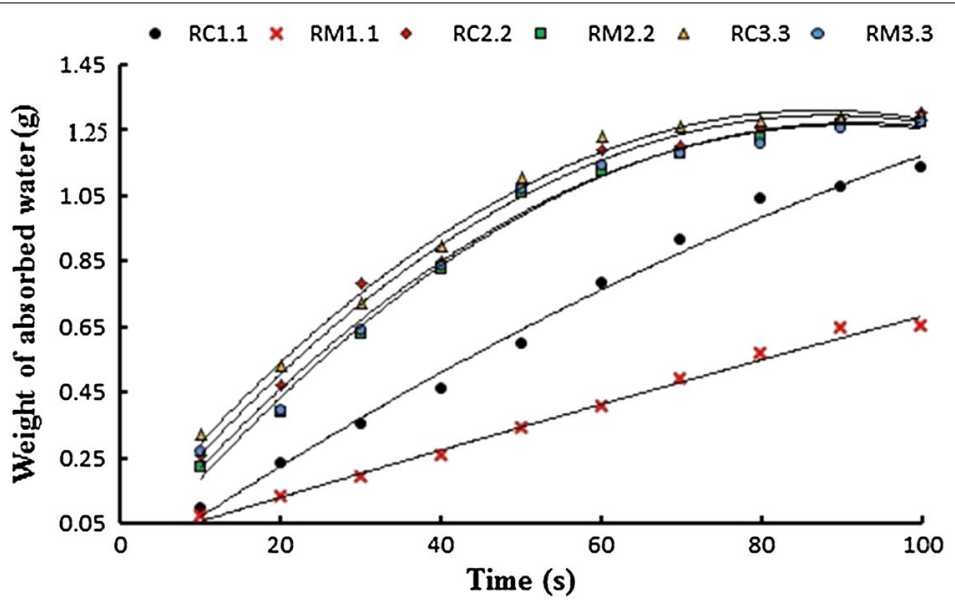

Fig. 7 Effect of fibre linear density and yarn type on water absorbency.

The effect of fibre linear density on water absorbency of test fabrics is presented in Fig. 7. Water absorbency was observed to increase with the increase in polyester fibre linear density for both carded (RC3.3 > RC2.2 > RC1.5 > RC1.3 > RC1.1) and combed yarn fabrics (RM3.3 > RM2.2 > RM1.5 > RM1.3 > RM1.1). Increase in water absorbency with fibre linear density may be attributed to corresponding increase in fabric thickness and fabric porosity (Table 4). For the same yarn fineness, as the fibre fineness decreases, the number of fibres in yarn cross-section decreases, which may result in increased yarn bulkiness and availability of high pore volume in yarn structure. Large pores or a high total pore volume assists in higher liquid volume retention, as suggested by Varshney et al. (2010). An increase in water absorbency of fabrics with increase in fibre linear density is therefore well justified in the light of above arguments. Combination of polyester fibre of higher decitex and carded yarn is seen to result in fabrics of higher water absorbency.

\section{Conclusions}

Plated knit structures are characterized by distinct yet integrated inner and outer layers. Selection of contrastingly different fibre and yarn components in distinct inner and outer layers is possible which ensure dry skin microclimate and maximum wearer comfort. The present study was undertaken with an aim to explore suitable combination of fibre and yarn variables for engineering polyester-cotton plated fabrics with good thermophysiological properties. Categorical variables i.e. outer layer yarn type and inner layer fibre linear density were found to affect the thermal, moisture vapour and liquid moisture transfer properties of developed test samples.

Plated fabrics knitted with carded yarn and polyester fibre of high linear density showed higher thermal resistance and would feel warmer on initial skin contact owing to low thermal absorptivity. However, the air permeability and moisture vapour transmission rate increased with combination of combed cotton yarn in the outer and coarse polyester fibre in the inner layer.

Combed yarn fabrics were superior in trans planar wicking compared to carded yarn counterparts. Water absorbency of fabrics with carded cotton yarn and coarse polyester fibre yarn was higher due to increased fabric thickness and porosity. 
It can therefore, be concluded that plated fabrics with combination of carded yarn in the outer layer and coarse polyester fibre in the inner layer may be suitable for cold and dry conditions owing to high thermal resistance, warm feel next to skin and high water absorbency.

Plated fabrics incorporating combed yarn and coarse polyester fibre seem suitable choice in warm and humid conditions based on their superior air permeability, better moisture vapour and liquid moisture transmission properties.

\section{Author details}

${ }^{1}$ Department of Fashion and Apparel Engineering, The Technological Institute of Textiles and Sciences, Bhiwani 127021 , India. ${ }^{2}$ Department of Textile Technology, Indian Institute of Technology Delhi, Hauz Khas, New Delhi 110016, India.

Received: 4 March 2015 Accepted: 5 August 2015

Published online: 23 September 2015

\section{References}

Ansari, N., \& Kish, M. (2000). The wicking of water in yarn as measured by electrical resistance technique. Journal of the Textile Institute, 91, 410-419.

Cimilli, S., Nergis, B. U., Candan, C., \& Ozdemier, M. (2010). A comparative study of some comfort properties of different fibre types. Textile Research Journal, 80, 948-957.

Das, B., Das, A., Kothari, V. K., Fanguiero, R., \& Araujo, M. (2007a). Moisture transmission through textiles. Part I: Processes involved in moisture transmission and the factors at play. Autex Research Journal, 7, 100-110.

Das, A., Kothari, V. K., \& Balaji, M. (2007b). Studies on cotton acrylic bulked yarns and fabrics. Part-I: Yarn characteristics. Journal of the Textile Institute, 98, 261-267.

Das, B., Das, A., Kothari, V. K., Fanguiero, R., \& Araujo, M. (2008). Effect of fibre diameter and cross-sectional shape on moisture transmission through fabrics. Fibers and Polymers, 9, 225-231.

Das, B., Das, A., Kothari, V. K., Fangueiro, R., \& Araujo, M. (2009). Studies of moisture vapour transmission through PV blended fabrics. Journal of the Textile Institute, 7, 588-597.

Erdumlu, N., \& Saricam, C. (2013). Wicking and drying properties of conventional ring and vortex spun cotton yarns and fabrics. Journal of the Textile Institute, 104, 1284-1291.

Holcombe, B. V., \& Hoschke, B. N. (1983). Dry heat transfer characteristics of underwear fabrics. Textile Research Journal, 53, $368-374$.

Kissa, E. (1996). Wetting and wicking. Textile Research Journal, 66, 660-668.

Nasrin, A., \& Nahida, A. (2011). Effect of combed and carded yarn on weft knitted finished fabric quality. International Journal of Engineering \& Technology, 11, 113-119.

Nyoni, A. B., \& Brook, D. (2006). Wicking mechanisms in yarns-the key to fabric wicking performance. Journal of the Textile Institute, 97, 119-128.

Oglakcioglu, N., \& Marmarali, A. (2010). Thermal comfort properties of cotton knitted fabrics in dry and wet states. Tekstil Ve Konfeksiyon, 3, 213-217.

Oner, E., Atasagun, H. G., Okur, A., Beden, A. R., \& Durur, G. (2013). Evaluation of moisture management properties on knitted fabrics. Journal of the Textile Institute, 104, 699-707.

Ozdil, N., Marmarali, A., \& Kretzchmar, S. D. (2007). Effect of yarn properties on thermal comfort of knitted fabrics. International Journal of Thermal Sciences, 46, 1318-1322.

Pac, M., Bueno, M., Renner, M., \& Kasmi, S. (2001). Warm-cool feeling relative to tribological properties of fabrics. Textile Research Journal, 71, 806-812.

Patil, U. J., Kane, C. D., \& Ramesh, P. (2009). Wickability behavior of single knit structures. Journal of the Textile Institute, 100 457-465.

Raj, S., \& Sreenivasan, S. (2009). Total wear comfort index as an objective parameter for characterization of overall wear ability of cotton fabrics. Journal of Engineered Fibers and Fabrics, 4, $29-41$.

Ramakrishnan, G., Dhurai, B., \& Mukhopadhyay, S. (2009). An investigation into the properties of knitted fabrics made from viscose microfibers. Journal of Textile \& Apparel, Technology and Management, 6, 1-9.

Singh, M. K., \& Nigam, A. (2013). Effect of various ring yarns on fabric comfort. Journal of Industrial Engineering. 1-7. doi:10.1155/2013/206240.

Tyagi, G. K., Krishna, G., Bhattacharya, S., \& Kumar, P. (2009). Comfort aspects of finished polyester-cotton and polyesterviscose ring and MJS yarn fabrics. Indian Journal of Fibre \& Textile Research, 34, 137-143.

Varshney, R. K., Kothari, V. K., \& Dhamija, S. (2010). A study on thermo-physiological comfort properties of fabrics in relation to constituent fibre fineness and cross-sectional shapes. Journal of the Textile Institute, 101, 495-505. 